\title{
Pattern of course of psychosis and diagnostic stability did not differ by ethnic family background
}

Harrison G, Amin S, Singh SP, et al. Outcome of psychosis in people of African-Caribbean family origin. Population-based first-episode study. Br J Psychiatry 1999 Jul;175:43-9.

QUESTION: What is the 3 year pattern of recovery and diagnostic stability among African-Caribbean patients with a first episode psychosis?

\section{Design}

Inception cohort followed up for 3 years.

\section{Setting}

Population based study in Nottingham, UK.

\section{Patients}

166 patients aged 16-64 years (mean age 31 y, 59\% men, 25\% African Caribbean family origin) with a first episode psychosis identified between June 1992 and May 1994.

\section{Assessment of prognostic factors}

At baseline, a diagnosis was made using ICD-10 and $D S M-I I I-R$ criteria and sociodemographic data were collected. African-Caribbean status was defined by patients' and parents' place of birth.

\section{Main outcome measures}

Pattern of course of psychosis (including symptoms, social disability, course, type, and resource use) and diagnostic stability.

\section{Main results}

Some information on course and outcome of the psychosis was available for $97 \%$ of patients. None of the 3 year outcome variables (scores on the Schedules for
Clinical Assessment in Neuropsychiatry, Scale for the Assessment of Negative Symptoms, Psychiatric Disability Assessment Schedule, and the Global Assessment of Function scale) showed statistically significant differences in the number or severity of positive symptoms or social disability between African-Caribbean patients $(n=33)$ and those of other ethnic origins $(n=133)$. The number of psychiatric admissions (mean difference -0.4, $95 \%$ CI -1.0 to 0.2 ) and duration of first admissions were also comparable between the 2 groups. Diagnostic profiles were similar, with no evidence of greater diagnostic instability in the African-Caribbean group $(75 \%$ of ICD-10 schizophrenia cases were stable in the AfricanCaribbean group, which was comparable with that in the non-Caribbean group). After adjustment for sex, social class, age, diagnosis, and duration of untreated illness, pattern of illness course was similar between AfricanCaribbean patients and non-Caribbean patients (adjusted odds ratio on the Operational Criteria Checklist course type: partial recovery or continuous chronic $v$ single episode or good recovery $0.6,95 \%$ CI 0.2 to 1.7 ).

\section{Conclusion}

Pattern of course of psychosis and diagnostic stability did not differ by ethnic family background.

\section{COMMENTARY_continued from previous page}

Harrison et al were able to define a group of patients of Caribbean origin. Illness course in this group, however, was compared with all other ethnic groups lumped together. Although their previous publications suggest that the number of patients of African and Asian origin was small, no data are given on the origin of the white patients. Their groups, however, are clearly more homogeneous ethnically than the ones in the study of Goater $e$ al and as such constitute a more relevant contrast clinically.

Neither study reports how large a difference in course they expected to find, nor how large their study samples needed to be to be able to detect such a difference. If we assume a clinically relevant effect size of 2 -that is, the odds of a single episode/good recovery is 2 times higher in African-Caribbean patients-then the study by Harrison et al would have had approximately $40 \%$ chance of detecting it. On the other hand, they would have had 85\% chance of detecting an effect of 3.

So what can clinicians conclude from these 2 studies? If we wish to know whether ethnic minority status, for example African-Caribbean ethnic group, is associated with a more benign illness course which, though not hugely different, may still constitute a large enough difference to make it relevant clinically, we must (1) make sure that the ethnic composition of the comparison groups matches the hypothesis, and (2) make sure we have a large enough sample to be able to detect it.

Source of funding: National Health Service Executive (Trent Research E Development), UK.

For correspondence: $D$ G Harrison, Division of Psychiatry, University of Bristol, 41 St Michael's Hill, Bristol BS2 8DZ, UK Fax +44 (0) 1179 279709. 